\title{
Implementing Long-Term EAP Follow-up with Clients and Family Members to Help Prevent Relapse-With Implications for Primary Prevention
}

\author{
Andrea Foote, Ph.D., ${ }^{1,4}$ Bradley Googins, Ph.D., ${ }^{2}$ Michael Moriarty, \\ ACSW, ${ }^{1}$ Claudia Sandonato, ACSW, Jerome Nadolski, ACSW, ${ }^{3}$ and \\ Claudette Jefferson, ACSW ${ }^{3}$
}

\begin{abstract}
This paper reports on a study in progress which involves (a) regular post-treatment contact by employee assistance program (EAP) staff with employees who seek help through the EAP, and (b) contact with a family member or other support person designated by the employee. The contacts are designed to provide support for maintenance of therapeutic gains, assistance in adjusting to current life situations, and early identification and prevention of relapse. The study will evaluate the process of initiating these contacts and will examine their effectiveness at reducing relapse. Factors associated with implementing these services in an EAP context are discussed.
\end{abstract}

KEY WORDS: Employee assistance program; relapse prevention; family.

Much of what has been reported in the literature on employee assistance programs (EAPs) has focused on intervening early in the process of addiction. EAPs were developed as mechanisms for early identification of employees with alcohol, drug, and mental health problems, and for secondary and tertiary prevention of health consequences associated with those problems (Shain \& Groeneveld, 1980; Blum, 1988; Presnall, 1981; Erfurt, 1990). The preponderance of EAP literature has focused on the front end

\footnotetext{
${ }^{1}$ Institute of Labor \& Industrial Relations, The University of Michigan.

${ }^{2}$ Center on Work and Family, Boston University.

${ }^{3}$ Employee Assistance Program, Detroit Edison Company.

${ }^{4}$ Address correspondence to Andrea Foote, Ph.D., Worker Health Program, University of Michigan, ILIR, III Catherine, Ann Arbor, MI 48109-2054.
} 
of the recovery process-e.g., the role of the supervisor in identification and constructive confrontation; the process of referral. This attention to factors essential in getting the alcoholic client into treatment is necessary, but not sufficient in a comprehensive approach to substance abuse recovery.

Analysis of the "back end" of this process has focused on the treatment phase, and finds relatively poor outcomes. Only a minority of patients treated for alcohol or drug dependence remain abstinent for six months after treatment (Armor, Polich, \& Stambul, 1987). However, employed alcoholics tend to do better than the unemployed (Braunstein, Powell, McGowan, \& Thoreson, 1983). This is thought to be due in part to the nature of the workplace and its ability to identify employees at an early stage while the supports available through the workplace are still an integral part of the alcoholic's life.

Most EAPs include procedures for casefinding or client identification, confrontation or motivation to enter the program, intake and assessment, and referral for treatment or assistance as appropriate. This similarity of reported EAP activities is greatly misleading, however. Surveys of EAPs reveal a wide range of program descriptions, locations, staffing arrangements, and client processing procedures (Erfurt \& Foote, 1985; Archambault, Doran, Matlas, Nadolski, \& Sutton-Wright, 1982; Roman, 1988), producing considerable variation in client outcomes (Foote, Erfurt, Strauch, \& Guzzardo, 1978; Kurtz, Googins, \& Howard, 1984).

This paper discusses the process of implementing two EAP activities that are designed to support recovery and reduce relapse: post-treatment EAP follow-up with the client, and post-treatment family involvement with the EAP. While the services focus on secondary prevention, working with employees at risk of relapsing or developing additional problems, they may have implications for primary prevention as well.

\section{LITERATURE ON POST-TREATMENT FOLLOW-UP SUPPORT}

Evidence for the effectiveness of aftercare in the treatment of alcoholism is not conclusive. Some studies show positive effects (Chvapil, Hymes, \& Delmastro, 1978; Pokorny, Miller, Kanas, \& Valles, 1973; Moberg, Krause, \& Klein, 1982; Costello, 1980), and some do not (Finney, Moos, \& Mewborn, 1980; Davidson, 1976; Kirk \& Masi, 1978). However, most of these studies have serious methodological flaws, and they have paid minimal attention to the process of getting patients to accept and take part in aftercare (Foote \& Erfurt, 1988). 
Typically participation in treatment-based aftercare is low. It is difficult to get patients to maintain a long-term relationship with a treatment facility. Rather than expecting treatment facilities to conduct aggressive outreach activities to maintain employed people in aftercare, it may make sense to provide post-treatment support at the worksite, through the EAP. Not only does the worksite have a potential financial interest in supporting such activities, the worksite also has access to its employees, while treatment facilities do not.

EAPs are not staffed to provide in-depth clinical counseling over a long period of time. While there is a substantial literature on relapse prevention methods in the context of treatment (Marlatt \& George, 1984; Chiauzzi, 1991), it is outside the scope of most EAPs to provide structured relapse prevention training. Nevertheless, the EAP can extend the treatment intervention to include long-term follow-up, providing routine monitoring and support services to employees after their initial treatment.

EAP clients frequently relapse, and some move in and out of treatment for years after program entry. This often occurs without the knowledge of the EAP staff when no long-term follow-up is conducted (Erfurt \& Foote, 1988). Where routine follow-up contacts are made by the EAP, however, relapse can be identified and addressed more quickly (Walsh, Hingson, Merrigan, et al., 1991).

While many EAPs indicate that they routinely follow up with their clients, there are wide variations across EAPs in activities undertaken under the label of "follow-up." The content and frequency of this follow-up is seldom specified, and in practice it appears that follow-up often is either non-existent, or is limited in duration or provided only to a few select clients.

The provision of follow-up counseling has not been widely tested in employee assistance programming, but there is evidence that worksite follow-up has a beneficial effect for other types of chronic conditions, such as hypertension, smoking, overeating, and high cholesterol (Caplan, Harrison, Wellons, \& French, 1980; Foote \& Erfurt, 1983; Logan, Milne, Achber, Campbell, \& Haynes, 1979; Alderman \& Stormont, 1979; Erfurt, Foote, \& Heirich, 1991). While the nature of the problems that bring employees to EAPs is different from hypertension, smoking, etc., often being more stigmatic, there are also similarities. Both types of problems are likely to be chronic in nature, requiring long-term management; patients in both groups have a tendency to drop out of treatment or relapse; and successful management of these problems can in both cases result in significant benefits to the employer as well as to the employee, making them appropriate targets for work-based follow-up programs. In addition, many of these problems can also be addressed with a prevention focus, with follow-up 
counseling targeting the prevention of other, related problems. Problems that bring employees to either EAPs or to health interventions can also benefit from primary prevention counseling and education. This emphasis is also an appropriate target, therefore, for work-based programs.

One randomized study has been conducted that examined the effects of EAP follow-up counseling with substance abuse clients for one year after treatment. The study found that clients receiving follow-up counseling did better than clients in regular care on measures related to substance abuse (number of substance abuse hospitalizations, health benefit claims for substance abuse treatment, and substance abuse disability claims). The effects were not statistically significant, but they were generally in the same size range as other predictors. Overall, the clients in the experimental group had $15 \%$ fewer relapses than clients in the control group, and utilized $23 \%$ less in substance abuse treatment costs, and $31 \%$ less in substance abuse disability costs (Foote \& Erfurt, 1991).

\section{LITERATURE ON POST-TREATMENT FAMILY CONTACTS}

The involvement of families in EAPs is even less common than posttreatment follow-up with clients. At present, there is no research which has examined the effects of post-treatment family involvement within an EAP context. Within the broader substance abuse treatment literature, however, a number of studies have directly addressed family involvement. Bauman, for example, has examined the difficulties of involving resistant family members in treatment (Bauman, 1981). Other studies discuss family dynamics within a family treatment perspective (Kaufman \& Pattison, 1981; Steinglass, 1980; Muchowski-Conley, 1982).

There is also a healthy literature on the broader issue of social support and its role in recovery. The environmental context for social support can influence whether the assistance offered to individuals is recognized as a resource which the individual can draw on for support (Coyne \& Delongis, 1986; Hall \& Wellman, 1985). Some studies have examined variables measuring support availability and its specific function in either promoting or impeding behavior change (Longabaugh, Beattie, Noel, Stout, \& Malloy, 1993; Zweben, 1991). In the alcoholism literature, the availability of social environments and supports is often suggested to be related to treatment outcome (Davidson, 1976; Booth, Russell, Soucek, \& Laughlin, 1992). The literature also has identified a number of supports that can affect behaviors negatively (Cahalan, 1978), including worksite structures and subcultures (Ames \& Janes, 1987; Googins, 1983). Social support has also been found to be effective in helping prevent dysfunctional behaviors, with workplace 
programs targeting parenting support networks, and other lifestyle health issues, for example. The prevention literature has shown repeatedly the value of social support in preventing a range of substance abuse behaviors as well as other related problems, for both youth and adult audiences.

A study examining the dynamics of alcoholism within families found that the husbands' alcoholism had a major impact on their wives, whether the wives were working or at home (Googins \& Casey, 1987). Two characteristics of the population in this study are of special interest. First, over half of all the wives were children of alcoholic parents, which in part may explain why they stayed in this relationship. Second, there were a number of alcoholic husbands whose families had already disintegrated by the time they got into treatment. Both of these factors speak to the need for introducing a family intervention within the treatment process at an early point in time, to assist the families who are a part of the alcoholic system, and to identify the family members who need assistance as much as the identified alcoholic, and whose treatment may be a key ingredient in the recovery process.

The critical importance of social supports in general, and family supports in particular, is well documented as it relates to treatment outcomes for alcoholics. While substance abuse treatment facilities generally encourage or require family involvement in treatment, they are not able to maintain long-term contacts with the families. EAPs have not included a family involvement component, nor has there been any research testing such a component within the EAP.

\section{STUDY DESIGN}

A study is underway in cooperation with the Detroit Edison Company's Employee Assistance Program (EAP) to look at the effects of both client follow-up and family involvement through the EAP. The study will involve approximately 400 EAP clients, randomly allocated to receive no long-term follow-up, follow-up contacts by the EAP counselors for two years after intake into the EAP, and/or EAP follow-up for two years with a family member or other support person identified by the EAP client. The study is designed to examine these services as prevention strategies, aimed primarily at preventing relapse, but also at developing skills within the employees and their family members to reduce incidence of new problems.

The general guideline for frequency of follow-up (for both clients and family members) is weekly for the first month, monthly for the next five months, bi-monthly for the next six months, and quarterly for the second year. Contacts revert to weekly in case of relapse or during a crisis period. 
However, this guideline is adjusted to the client's/family member's particular situation and needs. When there is no apparent need for continuing support (the client's problem was transient and easily addressed), brief telephone contacts are made to check in and make sure everything is $\mathrm{OK}$.

All follow-up contacts are seen as negotiations. At a minimum the counselor is negotiating when the client will come in next. The counselor may also be negotiating what the client is willing to do, in cases where the problem is not resolving. If the client is not ready to take action (seek help, etc.), the counselor may try to negotiate when he/she might be ready to try (or to try again).

\section{THE CONTENT OF FOLLOW-UP}

Follow-up contacts are structured as a progress review and update. Behaviorally specific goals are reviewed from the assessment and counseling, from any discharge plan or relapse prevention plan developed by a treatment facility, and from any specific objectives the client has identified.

When working with substance abuse clients, for example, we might review whether antabuse was recommended and how it is being used, what aftercare or self-help meetings are being attended, whether the client has experienced any urges since our last meeting, whether there have been any lapses, and so on. These topics are covered with both the client and the support person, and any significant differences in reports are identified and addressed as a potential problem. Any improvements are praised and reinforced.

Follow-up counseling is done face-to-face when possible, especially in the initial period after treatment, but we have found that telephone follow-up is nearly as effective. In some cases, telephone contacts are the only feasible way of staying in touch. Once trust has been established, it is possible to talk in depth on the phone. If there are signs of problems, we try to establish a face-to-face meeting as soon as possible.

A critical aspect of client follow-up is maintaining a balance between support and confrontation. In providing support, the EAP counselor emphasizes the importance of keeping in touch, whether things are going well or not so well. Some clients do not understand why they should see the EAP when they are doing well; others are ashamed to come when they are not doing well. The counselors try to establish the image of the EAP as a safety-net.

While always providing support, the EAP counselor must also be prepared to confront the client when the client or someone else has provided information indicating that all is not well. The counselor must be able to 
present this to the client so that the client understands the facts and their implications.

Several topics are covered at all follow-up contacts with the client, including (a) positive feedback for client's positive behavior changes, (b) discussion of slips or problems, in order to learn from failures when they occur, and (c) discussion of client's current work and home situation to help client identify any immediate concerns or problems, and make referrals for additional assistance if appropriate. These discussions should assist the client to identify high-risk situations and strategies for dealing with them, to review situations recently encountered and the client's responses, and to identify and build on the client's successes.

In implementing the family involvement component of the study, there is a critical balance between codependency and support. The EAP counselor must work with the family members to help them distinguish the difference. This can be facilitated by first finding out if the family member is involved in the same problems as the client (e.g., is using alcohol/drugs; having the same types of psychological or adjustment problems). If so, the counselor may need to deal with this person as a client and make appropriate referrals.

The counselor will then introduce the family member to the concepts of enabling and codependency by asking some questions such as: Are you familiar with the term "enabling"? Can you identify what activities are enabling? How do you perceive your role in supporting or enabling the client?

Once the family member has been oriented to the process, topics covered during follow-up contacts are similar to those covered with clients, including provision of positive feedback for positive behaviors reported or exhibited by family member, and identification of any work or home problems or concerns the family member may have related to the client's situation.

The study has been underway for approximately two years. No statistical results will be evaluated for another two years, when the last clients entering the study will have completed two years of follow-up. However, much has been learned about the process of implementing follow-up contacts with clients and family members. This paper reports on these findings, and draws conclusions based on the experience.

\section{Implementing Follow-Up with the Client and Family}

In this section we will discuss the following topics: initial concerns about implementing follow-up, when to introduce follow-up, adapting follow-up to the individual, selecting a good support person (family member), and orienting and coaching the support person. 


\section{Initial Concerns About Implementing Follow-Up}

Introducing the new protocol for client follow-up and family involvement initially created some anxiety within the EAP staff, because clients were asked to increase their EAP involvement and to broaden their exposure with the addition of family support, at a time of great anxiety company-wide. Even in good times when jobs are felt to be secure, employees may approach the EAP with concerns regarding potential stigma. Coming forward to deal with a problem, while seen as positive on the surface, can be construed by a client as evidence of weakness. Fear that the company will know that "something is out of control in my life" is frequently experienced, along with worry that this information could be used to discredit the employee.

In more difficult economic times such as occurred during the early study period, this anxiety may be intensified. As the company responds to external threats of increased competition with cost-cutting measures, downsizing and re-organization, fear for one's job is felt by virtually all employees. People are expected to work harder and smarter, while coping with feelings of acute vulnerability. Prompt help-seeking for personal or performance problems becomes all the more critical to sustain performance, but is perceived as more risky, since the employee feels that his/her efforts to project an image of health and competence may be undermined. Some socially-conscious corporations have taken a more proactive stance in helping employees deal with the anxiety and stress related to economic cutbacks, and with the need to relocate or find new employment. Such education and health programs represent a prevention orientation, and may bring positive outcomes both for the company and for the employees involved.

The EAP counselors feel the same vulnerabilities as the employees they serve. Changes in the company culture and the manifold anxieties they produce are met daily in the EAP office. The staff, actively sensitized to the issues and pressures facing employees, are prepared to protect the employee from anything that would add additional stress or vulnerability.

With so much felt to be on the line, the EAP staff struggled with just how best to introduce these new follow-up services to clients who might wish only a minimal and circumscribed involvement with the EAP. Since many clients would wish that no one else know of their contact with the EAP, family involvement was thought to be especially troublesome. Also, a hesitant employee pushed too hard might complain through company or union channels, causing potential trouble for the EAP.

Consequently the study raised a number of questions for the EAP counselors. Would clients respond favorably to on-going contacts with the 
EAP, or would this heighten anxiety? Most clients, it was agreed, would probably feel safe with a two-year involvement with the EAP, but how they would react to suggested family involvement was another matter. How should this be offered to clients? Should it be offered as a new service? As research? Should we sell hard, or should we make it easy to opt out when clients hesitate? Should we expect cooperation, or merely suggest it? If the employee resists, should we pursue participation at a later date? What are the limits?

These are a sample of the concerns that surfaced within the EAP team as the study began. Experience has shown that these worries were excessive. Most clients have responded favorably to the concern and care of the EAP counselors, and trust in the individual counselor has been the key in developing this team effort to maintain recovery. As the counselors became more comfortable in the knowledge that follow-up and family involvement are found to be helpful rather than intrusive, encouraging participation became natural.

\section{When to Introduce Follow-Up}

The question of when to discuss long-term follow-up and family involvement with the client seemed difficult at first. At the start of the study the EAP staff had a tendency to wait until treatment was completed. This proved ineffective, because some clients do not return to the EAP unless previous arrangements have been made. In addition the EAP counselor may forget to introduce the subject if there is no clearly specified time when this should be done.

Experience has shown that follow-up contacts should be introduced at the end of the first session with the client. There are three reasons for this. First, you may not see the client again if you have not programmed additional contacts. Some clients will accept your referral to treatment and see no reason to come back to the EAP. Second, some clients fail to follow through on referrals to formal treatment, but will agree to come back to the EAP for follow-up visits. Third, introducing the subject is awkward after treatment has begun. If follow-up contacts and family involvement are important parts of the EAP service, this should be discussed up front. Raising it later implies that it is only an afterthought and is of little value.

In the vast majority of cases it is possible to discuss this in the first meeting with the client, the exception being an emergency situation in which the client is in no condition to deal with anything beyond the immediate difficulty. Each client is assured the right to refuse follow-up par- 
ticipation or family involvement at any time, and is asked to sign a consent describing his or her participation in the study.

We have found that most clients are very grateful for the help that the EAP provides, and are happy to participate in further service. Even employees who were sent to the EAP because of work performance problems have responded positively. For those employees who decline long-term involvement with the EAP, we ask them to think about it, and reintroduce the possibility at a later date.

\section{Adapting Follow-Up to the Individual}

While the general follow-up design was set in advance as described above, clients show various levels of acceptance for a long-term relationship with the EAP. Some clients will take all the help they can get and are amenable to any frequency of follow-up contacts, but others are reluctant to make a commitment.

Reluctant clients tend to say that they prefer to handle their problem by themselves. Our approach with these clients is (a) to respect their position, (b) to offer the follow-up contacts benignly, (c) to emphasize our goal of giving good service, and (d) to indicate that we are trying to learn more about how to provide good service, and they may find that they benefit also.

Clients are not asked to commit themselves to a certain frequency of follow-up; the frequency is negotiated at each step. Thus clients who are initially reluctant or suspicious have a chance to become familiar and comfortable with the process, and to trust that nothing bad will result.

\section{Selecting a Good Support Person}

The choice of a support person from among family or friends poses interesting issues. The problems that clients bring to the EAP almost always affect and are affected by the people surrounding them. The support person is most often a family member, and the terms "support person" and "family member" are used interchangeably in this paper. However, some clients no longer have intact families and must look elsewhere for support.

Among married clients the support person is most often the spouse, but in some cases the spouse is not the best choice. When there is reason to believe the spouse will not be able to assist the client in maintaining recovery, other choices should be considered. One married client in the study selected his mother as a support person; another used a sister, and 
others chose close friends. Unmarried clients have selected a similar array of support people - a parent, a niece, a friend, an AA sponsor.

The process of selecting a support person can itself be therapeutic for clients. It can help them assess their network of relationships and identify the people from whom various types of support can be sought for various purposes. It can also identify the people in their network who will likely not be supportive, allowing the client to focus on reasons for this lack of support and ameliorative actions the client might decide to take to repair damaged relationships. Finally, the process can identify clients who have no working support network, and developing such a network can become an important focus of recovery.

The following characteristics should be sought when selecting a support person: a generally helpful nature, a good listener, a positive relationship with the client, someone who is able to be objective in assessing situations, able to confront the client with difficult information, and someone who is likely to be open to coaching by the EAP counselor. In addition, of course, the client must be comfortable with and trust the support person.

\section{Orienting and Coaching the Support Person}

Both the client and the family member/support person must be oriented to the follow-up process. Most people assume that a health problem will be "cured" through some recommended course of treatment, and they seldom consider the long-term nature of recovery for many types of problems, nor the prevention of relapse. In introducing follow-up, the EAP counselor discusses the EAP's desire to help people stay healthy.

It is preferable to orient the client and family member together, if possible in a face-to-face meeting. If travel constraints are severe or schedules do not allow for such a meeting, the employee may discuss the program with the family member, and tell the person to expect a phone call from the EAP counselor. During the call the family member is oriented and a schedule of contacts is established.

Initial orientation to the program includes a discussion of how the family member can be supportive of the client's recovery, eliciting ideas from the family member as well as suggestions from the EAP counselor. The support person's perceptions of the client are also discussed, in order to establish the person's frame of reference. The future procedure is then outlined, including the nature and timing of future contacts and toward what goals. During the process the EAP counselor reinforces the importance of the role of the support person. 
The EAP counselor acts as a "coach" for the support person. Coaching is done at two levels. First, at the initial meeting the EAP counselor must explain why family involvement and support are important. The support person may have been given misinformation by the employee, and this explanation helps the support person become a part of the team effort.

Second, at each contact with the family member, the EAP counselor should encourage him or her to maintain supportive contacts with the client. Over time, most support people will have a tendency to reduce their contacts with the client regarding the identified problem and procedures for maintaining healthy behaviors. It is not unusual during a call with a support person to get a response such as "I'm glad you called. I've been so busy, I'm afraid that I haven't talked to (CLIENT'S NAME) about this in a couple of weeks. I'll talk to him tonight."

\section{RESULTS}

It will be another two years before study results are completed and analyzed. However, after two years of experience in implementing posttreatment follow-up contacts with clients and family members, we have made a number of observations about the impact of these contacts in supporting recovery.

\section{What Happens When You Involve Families?}

Clients who seek help through the EAP are accessing a support service. The EAP will typically either provide short-term counseling or refer the client to a source of treatment. However, the EAP can define its role more broadly as facilitating a support network which includes not only the EAP counselor and treatment staff, but also friends or family, and in some cases, supervisors, co-workers, or others at the worksite.

The EAP is better placed than any of these other sources of support to facilitate a team approach. While treatment personnel are capable of doing this, their services are time-limited, and they do not have any direct involvement with the client's everyday life. The EAP is accessible to the client and knowledgeable about a substantial part of the client's lifehis/her worklife. If the EAP can successfully involve a family member as well, each major sector of the client's life is represented in an effort to help the client recover, with everyone working in the same direction.

Moreover, such an effort by the EAP causes the client and family to believe that the company really cares about them. We had feared that fol- 
low-up with a family member might be considered as intrusive by the client or family. On the contrary, we have received many grateful comments from both clients and family members in support of this process. The family members indicate that they feel a part of the recovery process and that they are happy to have a role to play in the client's success.

Family members are often our eyes and ears when problems recur. They will let us know when the client is in difficulty, and facilitate an early intervention before a crisis or full relapse occurs. These contacts, of course, happen with the full understanding and signed consent of the client. We do not view family members as spies who report secretly on the client's behavior. Rather, they are part of the team that assists the client to maintain recovery.

However, family involvement does more than help a client maintain recovery; it also uncovers surprises before they have developed into crises. For example, one client came to the EAP about his son, whom he thought was an addict. In the normal course of events we would have counseled this client about how to deal with his son, and given him information on sources of treatment for the son. Because of the family involvement component of the study, however, we got the client to bring his son to the EAP. In the interview it was found that the son had a serious alcohol problem. When the EAP counselor asked the son who else in the family had an alcohol problem, he turned to his father, who denied he had a problem. The father named his wife as a support person. The wife/mother came into the EAP, very depressed and exhibiting signs of both codependence and denial, especially with regard to the son. These conversations opened up a very different picture of the family. It facilitated getting all three people into treatment, and placed a different context on subsequent follow-up counseling which addressed not just the son's recovery, but recovery of the entire family.

Involvement of the family changes the way in which the EAP is viewed by the client. Rather than being seen only as a source of referral to treatment, it becomes the central contact for all treatment-related issues, often including problems with insurance coverage.

\section{Which Clients Benefit Most from Follow-Up?}

At the end of the study we will look empirically at which clients benefited the most from follow-up and from family involvement. However, our experience so far has produced several hypotheses about this. First, we believe that substance abuse clients are especially likely to benefit from follow-up counseling. They tend to be enthusiastic and cooperative when they 
first come out of treatment, and it is easy to establish a long-term relationship. The signs of impending relapse are generally easy to identify. While this relapse often occurs within a few months of completing treatment, we have worked with cases who relapsed a year later. We believe that at least two years of follow-up are needed.

A second group that benefits greatly from follow-up are people prone to crises. These people are easy to identify based on their histories. The EAP counselor can work to prevent a crisis from occurring by maintaining contact on an on-going basis, helping the client to identify danger signs, and working toward early problem resolution. Such activities and programming can also serve a prevention focus, by reducing the potential onset or exacerbation of many individual and family problems or crises. This prevention focus teaches coping, changing and enhancing strategies, often before intervention is necessary.

A third group that benefits are those with on-going job or family stressors. The EAP can support these people over time, helping them to develop positive ways to handle situations and identifying their strengths and sources of support.

There are also EAP clients whom we think will NOT benefit from follow-up support. These include primarily those employees who are seeking only information. Many employees come to the EAP with questions about job training or advancement, or to get information about sources of child care, elder care, and the like. Some come with questions or problems related to their health benefits. If the client's problem is essentially addressed through the provision of information or solution of an immediate problem, then follow-up support is probably not warranted.

\section{Which Clients Benefit Most from Family Involvement?}

In general, the clients who will benefit from follow-up will also benefit from family involvement. For substance abuse clients, the family can be an important source of support and relapse prevention. Many treatment programs will try to educate family members about signs of relapse and how to handle the situation. But regular involvement with the EAP after completion of treatment will give the family member a coach who can help evaluate a situation that concerns the family member and plan a strategy to intervene if necessary. In addition, contact between the family and the EAP creates a link between two major spheres of the employee's life and helps sustain a team approach to recovery. 
Another specific group that benefits from family involvement is people with depression. These people often want to withdraw, and this is harder to do when a family member is involved.

Both follow-up and family involvement can be difficult to attain when the client is already involved in treatment at the time he/she comes to the EAP. This can occur when clients are referred to the EAP by the supervisor or company medical department. Because the EAP was not involved from the beginning, these clients may resist developing any long-term support from the EAP.

Family involvement is difficult and sensitive when there are severe marital problems, but can ultimately be quite beneficial to long-term recovery. If the couple is not receiving help for their problems, contacts with the EAP can become crisis intervention or marital counseling, although this is not the intent. Such counseling can ultimately result in acceptance of treatment.

In one case, an EAP client brought his wife in as his support person, and it became evident that she had serious mental problems. Violence was beginning to erupt at home, and almost did in the EAP office. The EAP counselor was able to get both people into therapy, and once the situation stabilized, follow-up with both people became productive.

In another case, an employee came to the EAP depressed due to a demotion at work that had happened to him as well as others in his department. Because this was a work-related problem, a contact with family would normally be very unlikely. However, the client's wife came in as his support person and revealed long-standing marital problems. The EAP counselor conducted some brief marriage counselling sessions with the two, and the wife decided to take some assertiveness training. Both now report that the marriage is better than ever and the husband is adjusting to the work situation.

These examples reveal two things. First, people with problems in one sector of their life may well be having problems in another sector as well. Family involvement can facilitate early identification of these problems. Second, the identified support person may well have conflicts with the client, but this does not necessarily mean that he or she is a poor choice. Working through problems with the support person can be very useful, and the person can in fact be very supportive in other areas of the client's life.

\section{CONCLUSIONS}

Our experiences so far in implementing follow-up and family involvement have reaffirmed our sense that these services can significantly improve 
recovery, and may even help prevent future problems. We have seen clients for whom we were able to prevent relapse or catch it at an earlier stage than would have occurred without the follow-up, potentially saving the client's job, health, marriage, etc. We have also identified other problems not presented by the client and often unrelated to the presenting problem, including problems with alcohol, family, or marital relations. Finally, we have found that clients are more likely to come to the EAP with a new problem or potential relapse if they have had regular follow-up contact with the EAP counselor, perhaps preventing more serious outcomes.

While a more formal conclusion must await a statistical analysis at the end of the study period with a consideration of costs as well as benefits, it does appear that long-term client follow-up and family involvement with the EAP are effective secondary prevention strategies. Whether these services also produce primary prevention is not clear. We hypothesize that working with both the client and a support person will improve their abilities to cope in healthy ways, but there is no evidence at this point in the study to support this. The issue will be examined further at the end of the study when more data are available however.

One may ask whether the EAP is simply duplicating services that are being provided by the treatment community. Our observations discussed above may simply reflect the fact that the EAP is more aware of what is happening in these families. It is possible that the treatment facilities to which EAP clients are referred are effectively involving family members and assessing all spheres of the clients' lives.

However, because the EAP has access to clients over a longer period of time and also has better information about the clients' job situation, we believe that the services imbedded in client and family follow-up will be found to have been more effective in preventing relapse and supporting recovery than relying on treatment facilities. In addition, these services can also help prevent future, related problems for the client, and/or the family and co-workers.

The study is being conducted within the context of an internal EAP with offices at the company headquarters. Access to the EAP is easy for employees who work at the headquarters, and is facilitated at the large remote sites by having EAP counselors visit these sites periodically. However, many employees work at locations not visited by EAP staff. In this respect the EAP functions much like many external EAPs that provide services to people who are geographically dispersed and who would have difficulty in making regular visits.

While the study will not test the feasibility of providing follow-up services within the context of an external EAP, the barriers to doing this probably have less to do with having adequate access to the employees, and 
more to do with maintaining a competitive pricing structure. Even in the EAP under study, many follow-up contacts are done by telephone rather than in person. An EAP that was externally contracted rather than internally hired would be able to provide all of the services being tested in this study. However, it would require a contractual agreement that included payment for these services.

\section{Barriers to Long-Term Follow-Up}

We have identified some barriers or difficulties in providing these follow-up services. Long-term follow-up with clients and family members is time-consuming. The major barrier within the EAP to providing these services has been finding the time. New cases and crises cannot be turned away in order to provide follow-up support, and so follow-up always takes second place to initial assessment and crisis management. In addition, company policy requires special attention to certain cases such as those involving workers' compensation, lost work days, or job jeopardy.

There are also client-related barriers. Some employees can access the EAP readily by virtue of their work location and schedule, but others have more difficulty in arranging their work schedule to accommodate routine follow-up visits. A few clients hold beliefs about the nature of recovery that are incompatible with routine follow-up support. They may interpret follow-up counseling as an expectation that they will fail, or as fostering dependency. Some clients are frightened or distrustful of the EAP, and they attempt to limit the focus of their interaction to their job, while discounting any personal problems. Finally, it is impossible to involve a support person for some clients, because they cannot identify any support person that they trust.

All of these barriers can be addressed programmatically. However, it is first necessary to identify the degree to which this type of long-term involvement with the EAP actually makes a difference in recovery. Our experience so far suggests that it does, but statistical comparisons at the end of the study period will provide a better answer.

\section{ACKNOWLEDGMENT}

This research is supported by grant \#R01-DA05934 from the National Institute on Drug Abuse. 


\section{REFERENCES}

Alderman MH, Stormont B. (1979). "Work Site vs. Community Based Antihypertensive Care: A Controlled Trial.". Preventive Medicine, 8, 123.

Ames G, Janes C. (1987). "Heavy and Problem Drinking in an American Blue Collar Population: Implications for Prevention." Social Science in Medicine, 25, 949-960.

Archambault R, Doran R, Matlas T, Nadolski J, and Sutton-Wright D. (1982). Reaching Out: A Guide to EAP Casefinding. Troy, MI: Performance Resource Press.

Armor DJ, Polich JM, Stambul HB. Alcoholism and Treatment. (1987). New York: Wiley Interscience.

Bauman MH. (1981). "Involving Resistant Family Members in Therapy," in Questions and Answers in the Practice of Family Therapy. A. Gurman, ed. New York: Guilford, pp. 16-19.

Blum TC. (1988). "New Occupations and the Division of Labor in Workplace Alcoholism Programs." In M Galanter (ed.), Recent Developments in Alcoholism, Volume 6. New York: Plenum Press.

Booth B, Russell D, Soucek S, Laughlin P. (1992). "Social Support and Outcome of Alcoholism Treatment: An Exploratory Analysis." American Journal of Drug and Alcohol Abuse, 18, 87-101.

Braunstein WB, Powell BJ, McGowan JF, Thoreson RW. (1983). "Employment Factors in Outpatient Recovery of Alcoholics-A Multivariate Study." Addictive Behaviors, 8, 345-351.

Cahalan D. (1978). "Implications of American Drinking Practices and Attitudes for Prevention and Treatment of Alcoholism." In GA Marlatt and PE Nathan (eds), Behavioral Approaches to Alcoholism. New Brunswick, NJ: Rutgers.

Caplan RD, Harrison RV, Wellons RV, French JRP Jr. (1980). Social Support and Patient Adherence: Experimental and Survey Findings. Ann Arbor, MI: Institute for Social Research.

Chiauzzi EJ. (1991). Preventing Relapse in the Addictions: A Biopsychosocial Approach. New York: Pergamon Press.

Chvapil M, Hymes H, Delmastro D. (1978). "Outpatient Aftercare as a Factor in Treatment Outcome-A Pilot Study." Journal of Studies on Alcohol, 39, 540-543.

Costello RM. (1980). "Alcoholism Aftercare and Outcome-Cross-Lagged Panel and Path Analysis." British Journal of Addictions, 75, 49-53.

Coyne J, Delongis A. (1986). "Going Beyond Social Support." Journal of Consulting and Clinical Psychology, 54, 454-460.

Davidson A.F. (1976). "An Evaluation of the Treatment and After-Care of a Hundred Alcoholics." British Journal of Addictions, 71, 217-224.

Erfurt JC. (1990). "EAP and Wellness Program Follow-Up as Primary, Secondary, and Tertiary Prevention Strategies in the Workplace." In Roman PM (editor), Alcohol Problem Intervention in the Workplace: Employee Assistance Programs and Strategic Alternatives. Westport, CT: Quorum Books, pp. 277-296.

Erfurt JC, Foote A. (1985). "Variations in EAP Design." In: Francek JL, Klarreich SH, and Moore CE. (eds.), The Human Resources Management Handbook: Principles and Practice of Employee Assistance Programs. New York: Praeger Publishers, pp. 45-57.

Erfurt JC, Foote A. (1988). "Health Care Cost Containment Through Worksite Wellness Programs." In: Grimes CH (ed.), EAP Research: An Annual of Research and Research Issues, Volume II. Troy, MI: Performance Resource Press, Inc., pp. 33-51.

Erfurt JC, Foote A, Heirich MA. (1991). "Worksite Wellness Programs: Incremental Comparison of Screening and Referral Alone, Health Education, Follow-Up Counseling, and Plant Organization." American Journal of Health Promotion, 5, 438-448.

Finney JW, Moos RH, Mewborn RC. (1980). "Posttreatment Experiences and Treatment Outcome of Alcoholic Patients Six Months and Two Years After Hospitalization." Journal of Consulting and Clinical Psychology, 48, 17-29. 
Foote A, Erfurt JC. (1983). "Hypertension Control at the Work Site: Comparison of Screening and Referral Alone, Referral and Follow-Up, and On-Site Treatment." New England Journal of Medicine, 308, 809-813.

Foote A, Erfurt JC. (1988). "Posttreatment Follow-up, Aftercare, and Worksite Reentry of the Recovering Alcoholic Employee." In: Galanter, M. (ed.), Recent Developments in Alcoholism, Volume 6. New York: Plenum Press, pp. 193-204.

Foote A, Erfurt JC. (1991). "Effects of EAP Follow-Up on Prevention of Relapse Among Substance Abuse Clients." Journal of Studies on Alcohol, 52, 241-248.

Foote A, Erfurt JC, Strauch PA, Guzzardo TL. (1978). Cost-Effectiveness of Occupational Employee Assistance Programs: Test of an Evaluation Method. Ann Arbor, MI: ILIR, The University of Michigan.

Googins B. (1983). "Women Alcoholics in Management," Alcohol Health and Research World, 4(3).

Googins B, Casey J. (1987). "Dynamics of Alcoholism in Working Families," Alcoholism Treatment Quarterly, 4(3).

Hall A, Wellman B. (1985). "Social Networks and Social Support." Chapter in Social Support and Health (eds: S. Cohen and S.L. Syme). New York: Academic Press, pp. 23-41.

Kautman E, Pattison EM. (1981). "Differential Methods of Family Therapy in the Treatment of Alcoholism." Journal of Studies on Alcohol, 42, 951-971.

Kirk SA, Masi J. (1978). "Aftercare for Alcoholics-Services of Community Mental Health Centers." Journal of Studies on Alcohol, 39, 545-547.

Kurtz NM, Googins B, Howard WC. (1984). "Measuring the Success of Occupational Alcoholism Programs." Journal of Studies on Alcohol, 45, 33-45.

Logan AG, Milne BJ, Achber C, Campbell WP, Haynes RB. (1979). "Work-Site Treatment of Hypertension by Specially Trained Nurses: A Controlled Trial." Lancet, 1175-1178.

Longabaugh R, Beattie M, Noel N, Stout R, Malloy P. (1993). "The Effect of Social Investment on Treatment Outcome." Journal of Studies on Alcohol, in press.

Marlatt GA, George WH. (1984). "Relapse Prevention: Introduction and Overview of the Model." British Journal of Addictions, 79, 261-273.

Moberg DP, Krause WK, Klein PE. (1982). "Posttreatment Drinking Behavior Among Inpatients from an Industrial Alcoholism Program." International Journal of Addictions, $17,549-567$.

Muchowski-Conley PM. (1982). "Surveying the Need for Significant-Other Involvement in the Treatment of Female Alcoholism." International Journal of Addictions, 17, 1253-1258.

Pokorny AD, Miller BA, Kanas T, Valles J. (1973). Effectiveness of extended aftercare in the treatment of alcoholism. Quarterly Journal of Studies on Alcohol, 34, 435-443.

Presnall LF. (1981). Occupational Counseling and Referral Systems. Salt Lake City: Utah Alcoholism Foundation.

Roman PM. (1988). "Growth and Transformation in Workplace Alcoholism Programming." In: Galanter, M. (ed.), Recent Developments in Alcoholism, Volume 6. New York: Plenum Press, pp. 132-158.

Shain M, Groeneveld J. (1980). Employee-Assistance Programs: Philosophy, Theory, and Practice. Lexington, MA: Lexington Books.

Steinglass P. (1980). "A Life History Model of the Alcoholic Family." Family Process, 19, 211-226.

Walsh DC, Hingson RW, Merrigan DM, et al. (1991). "A Randomized Trial of Treatment Options for Alcohol-Abusing Workers." New England Journal of Medicine, 325, 775-782.

Zweben A. (1991). "Motivational Counseling with Alcoholic Couples in Motivational Interviewing: Preparing People to Change." In: Miller W (ed), Addictive Behavior. The Guilford Press, pp. 225-235. 